\title{
Effect of packaged strawberry juice on the surface roughness of nanofilled type composite resin
}

\author{
Rizky Amelia*, Opik Taofik Hidayat*, Denny Nurdin* \\ *Department of Conservative Dentistry Faculty of Dentistry Universitas Padjadjaran
}

\begin{abstract}
Introduction: The hard tissue of the teeth is resistant to heat and acid, so that the teeth have an important role as a material consideration of forensic dentistry. The humans have the same shape of the teeth around one in two billion. The stimuli of burn with high temperature and sour can be change the picture of macroscopic and microscopic tooth. This is the subject of an interesting comparison in the interests of justice and identification of dentistry. Methods: This research was a quasi experiment to know a change of microscopic teeth on the hard cases tooth-burning and the case hard acid treatment. The sample used were seven teeth, with details of one normal as a comparison, three teeth burned and three teeth soaked in a solution of water of accu. Observations were made using the microscope at 40x enlarged on each tooth. The tooth was documented by means of a photographed and compared with healthy teeth. Results: The results of this study was obtained by observing and comparing the microscopic structure and the obtained differences in the teeth and treated with the picture of normal teeth. Conclusion: Conclusion of this research is on the tooth are burned was visible loss of enamel at the cement-enamel junction as a result of the process of carbonization heat exposure so as to cause a breach of micro on the outer layer of the tooth enamel and thinning of dentin tubules, while the teeth are in the soak water accu (strong acid) seen change in color of enamel, micro cracks due to defective enamel and depletion of tubulus dentine and loss of boundary between the cementum and dentine.
\end{abstract}

Keywords: Tooth, Microscopic, Heat, Acid

\section{INTRODUCTION}

Strawberry is a plant belongs to the herbaceous fruit plant and belongs to the Rosaceae family. Strawberry (Fragaria sp.) is a popular fruit and is widely consumed because of its red color, its sweet and sour taste, and its various benefits. In the last decade there has been a significant increase in demand for strawberry juice because strawberry juice has an attractive aroma and color. Many people choose to consume packaged strawberry juice because it is more practical. ${ }^{1}$

Foods and drinks that contain strawberries are loved by many people around the world because they provide a variety of benefits, including improving heart health, reducing the risk of some cancers, helping the absorption of iron, helping the diet process which is good for diabetic patient, beautifying the skin, whitening the teeth, and improving brain and vision power. Strawberries can be consumed directly, made into fruit juice, processed into yoghurt or strawberry jam. ${ }^{1}$ 
Composite resins are often used as a restoration material to replace lost tooth structure. In addition, this material is also used to modify color and repair tooth contour for aesthetic purposes. There are several classifications of composite resin as restorative materials, one of which is a classification based on the average particle size of its main filler material, including macrofilled, microfilled, hybrid, and nanofilled type of composite resin. ${ }^{2}$

The nanofilled composite resin contains a very small-sized filler, which is about 5-20 nm consisting of zirconia-silica. The filler is in the form of nanomer and nanocluster particles. ${ }^{3}$ The combination of these two forms and the very small sized particle makes it easy to collect and produce a denser mass, resulting in an increase in physical properties. Its very small particle size allows this composite resin to be easier and smoother when polished. Therefore, nanofilled type composite resins are becoming popular nowadays. ${ }^{4}$

The nanofilled composite resin contains a very small filler, which is about $5-20 \mathrm{~nm}$ consisting of zirconia-silica. The filler is in the form of nanomer and nanocluster particles. The combination of these two shapes and the very small particle size makes it easy to be collected and produce a denser mass, resulting in an increase in physical properties. Its very small particle size allows this composite resin to be easier and smoother for polishing. Therefore, nanofilled type composite resins are becoming popular nowadays. ${ }^{5}$

Surface roughness of a restoration material is one of the important characteristics to be considered, because a rough surface of the restoration can facilitate plaque retention, causing staining on the restoration surface, and irritating the mucosa, until the aesthetics and oral health will be affected. Composite resin restorative materials will come into contact with chemicals contained in saliva, food, and beverages. ${ }^{6}$ If the composite resin is exposed to these chemicals continuously, the composite resin will experience wear and matrix degradation. Chemicals and acidic particles can cause degradation of the filler components, this depends on the damage from the bond between the matrix and the filler. ${ }^{7}$

Strawberries in the form of processed foods or drinks, contain acids and have a fairly low pH level. When the acidic packaged strawberry juice is being consumed oftenly, the condition in the mouth and the restoration of the composite resin will be affected. Packaged strawberry juice has a low pH level, which is around 2-3 because it has undergone a process of preservation. Based on this, the authors are interested in conducting research to find out whether the packaged strawberry juice affects the surface roughness of nanofilled type composite resin. ${ }^{1}$

\section{METHODS}

This type of research is purely in vitro experiment conducted to see whether there is an influence of packaged strawberry juice on the surface roughness of nanofilled type composite resin. The research population is nanofilled type composite resin.

The sample was a specimen of nanofilled type composite resin in disc shape with a diameter of $6 \mathrm{~mm}$ and a thickness of $3 \mathrm{~mm}$ total of 20 units, which are divided into two groups (each 10 specimens), namely: The group treated with the packaged strawberries juice and artificial saliva and control groups, which were only treated with artificial saliva. To support this research, several tools and materials were used in the manufacture of nanofilled type composite resin speciments, immersion of speciments in packaged strawberry juice and artificial saliva, and measurement of surface roughness.

The tools used in this study are as follows: Lightcuring Unit (LA 500 Blue Light, Apoza Enterprise, Taiwan), pH meter (Schott Instruments), composite resin specimen molds, petri dishes, tweezers, composite spatulas, plastic instruments, measuring glass, glass slab, timekeeper, heating stirrer (Heidolph, Germany), gloves, masks, Surface Roughness Tester (Surftest SJ-301, Mitutoyo), Stationery. The materials used in this study are as follows: Nanofilled type composite resin (3M ESPE FiltekTM Z350 $\mathrm{XT}$ ), packaged strawberry juice (Jungle Juice Diamond) with a pH of 3.07 , artificial saliva (Afnor Composition, can be seen in Table 1), Mylar matrix, cotton.

\section{RESULTS}

The following data are the results of the analysis 
of the effect of packaged strawberry juice on increasing surface roughness of nanofilled type composite resin:

In the table above, a summary of the two samples is seen, namely the effect of packaged

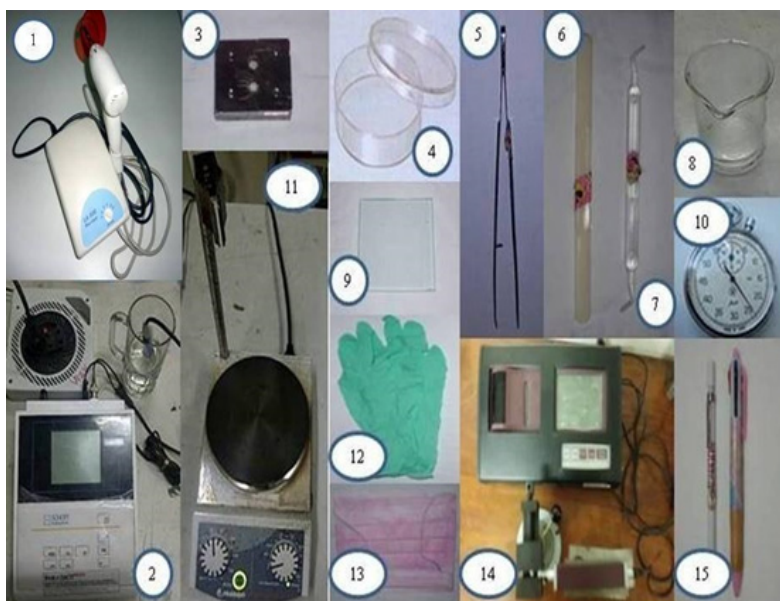

Figure 1. Research Tools: (1) Lightcuring Unit (LA500 Blue Light, Apoza Enterprise, Taiwan), (2) pH meter (Schott Instruments), (3) Composite Resin Specimen Mold, (4) Petri Dish, (5) Tweezers, (6) Composite Spatel, (7) Plastic Instruments, (8) Measuring Cups, (9) Glass Slabs , (10) Timers, (11) Heating Stirrers (Heidolph, Germany), (12) Gloves , (13) Masks, (14) Surface Roughness Tester (Surftest SJ-301, Mitutoyo), (15) Stationery.

Tabel 1. Komposisi Saliva Buatan (Afnor)

\begin{tabular}{ccc}
\hline No & Komponen & Jumlah \\
1 & $\mathrm{NaCl}$ & $0,7013 \mathrm{~g} / \mathrm{L}$ \\
2 & $\mathrm{KCl}$ & $1,1929 \mathrm{~g} / \mathrm{L}$ \\
3 & $\mathrm{Na} 2 \mathrm{HPO} 4$ & $0,2669 \mathrm{~g} / \mathrm{L}$ \\
4 & $\mathrm{NaHCO}$ & $1,4953 \mathrm{~g} / \mathrm{L}$ \\
5 & $\mathrm{KSCN}$ & $0,3304 \mathrm{~g} / \mathrm{L}$ \\
6 & Urea & $1,3213 \mathrm{~g} / \mathrm{L}$ \\
7 & $\mathrm{KH} 3 \mathrm{PO} 4$ & $0,2041 \mathrm{~g} / \mathrm{L}$ \\
\hline
\end{tabular}

Tabel 2. Angka Kekasaran Permukaan Resin Komposit Tipe Nanofilled (Kelompok Perlakuan dan Kelompok Kontrol)

\begin{tabular}{ccc}
\hline No & Kelompok Perlakuan & Kelompok Kontrol \\
\hline 1 & 0.408 & 0.186 \\
2 & 0.344 & 0.164 \\
3 & 0.334 & 0.210 \\
4 & 0.422 & 0.236 \\
5 & 0.352 & 0.200 \\
6 & 0.374 & 0.222 \\
7 & 0.364 & 0.206 \\
8 & 0.422 & 0.186 \\
9 & 0.342 & 0.238 \\
10 & 0.360 & 0.222 \\
\hline
\end{tabular}

strawberry juice on the surface roughness of nanofilled type composite resin with artificial saliva being the control. For the results of the influence of packaged strawberry juice on the surface roughness of nanofilled type composite

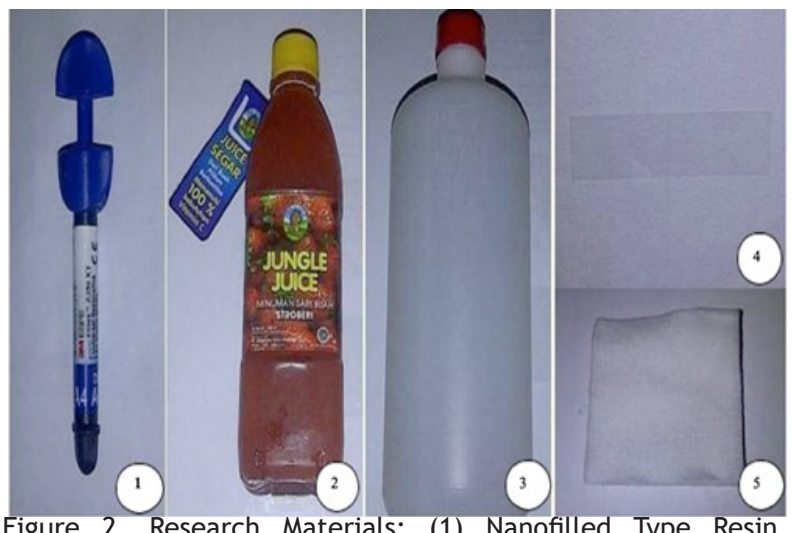
Composite (3M ESPE FiltekTM Z350 XT), (2) Packaged Strawberry Juice (Jungle Juice Diamond), (3) Artificial Saliva (Afnor Composition), (4) Matrix Mylar, (5) Cotton.

Tabel 3. Deskripsi Data Penelitian

\begin{tabular}{ccc}
\hline & $\mathbf{x}$ & $\pm \mathbf{s d}$ \\
\hline Kelompok perlakuan & 0,3722 & 0,0394 \\
Kelompok kontrol & 0,2070 & 0,0237 \\
\hline
\end{tabular}

resins, it has an average sample of 0.3722 with a standard deviation of 0.0394 . As for the results of the effect of artificial saliva as a control on the surface roughness of nanofilled type composite resins having an average sample of 0.2070 with a standard deviation of 0.0237 . For more details can be seen in the following picture:

Based on the data in Table 2, it will be tested whether the average population on the results of the comparison of the effect of packaged strawberries juice (treatment) and artificial saliva

Figure 3: Difference of average surface hardness of nanofilled type composite resins

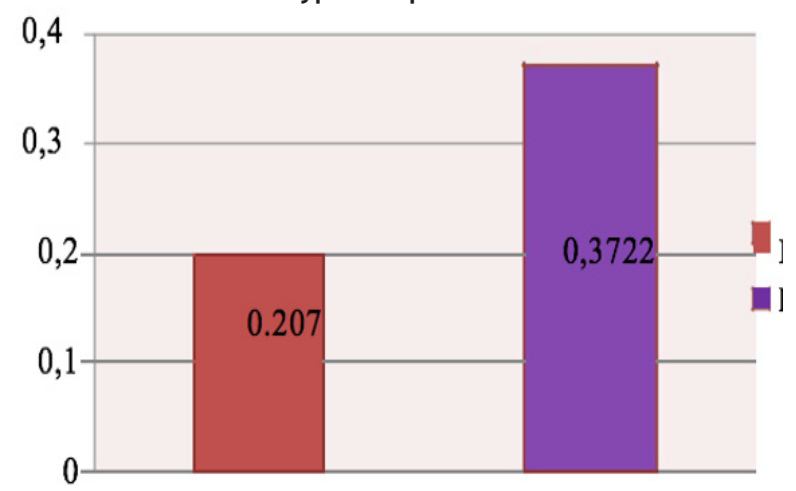


(control) on the surface roughness of nanofilled type composite resins is significantly different. So that the following results are obtained:

Based on Table 4, it is known that the t-table is 2.1 and the $t$-count is 11.311. Because $t$-count is greater than t-table, then Ho is rejected. Hence, with a $95 \%$ confidence level it is reasonable to state that there is a difference between the effect of packaged strawberries juice (treatment) and artificial saliva (control) on the surface roughness of nanofilled type composite resin. The average surface roughness of nanofilled type composite resins after being given strawberry juice in the packaging (treatment) is greater than that of artificial saliva (control).

Based on the average value of surface roughness, the percentage ratio of the difference between packaged strawberries juice (treatment) and artificial saliva (control) on the surface roughness of nanofilled type composite resin is $78.9 \%$. The percentage results indicate that there is an influence of packaged strawberry juice on the surface roughness of nanofilled type composite resin.

Based on Table 4, it is known that the t-table

Table 4. Average Difference Testing Results

\begin{tabular}{|c|c|c|c|c|c|c|}
\hline & $x$ & $\pm s d$ & t-count & $\begin{array}{l}\text { t-ta- } \\
\text { ble }\end{array}$ & Df & $\begin{array}{l}\text { Infor- } \\
\text { mation }\end{array}$ \\
\hline $\begin{array}{l}\text { Treat- } \\
\text { ment }\end{array}$ & 0.3722 & 0.0394 & 11.311 & 2.1 & 18 & $\begin{array}{l}\text { Ho } \\
\text { reject- } \\
\text { ed }\end{array}$ \\
\hline Control & 0.2070 & 0.0237 & & & & \\
\hline
\end{tabular}

is 2.1 and the $t$-count is 11.311. Because t-count is greater than t-table, then Ho is rejected. Hence, with a $95 \%$ confidence level it is reasonable to state that there is a difference between the effect of packaged strawberries juice (treatment) and artificial saliva (control) on the surface roughness of nanofilled type composite resin. The average surface roughness of nanofilled type composite resins after being given strawberry juice in the packaging (treatment) is greater than that of artificial saliva (control).

Based on the average value of surface roughness, the percentage ratio of the difference between packaged strawberries juice (treatment) and artificial saliva (control) on the surface roughness of nanofilled type composite resin is
$78.9 \%$. The percentage results indicate that there is an influence of packaged strawberry juice on the surface roughness of nanofilled type composite resin.

\section{DISCUSSION}

The desire to have a healthy lifestyle in modern society raises the consumption of fruit drinks. One of the most popular fruit drinks is the packaged strawberry juice because strawberries have a variety of health benefits. ${ }^{1}$ However, besides being healthy, fruit juice drinks including packaged strawberry juice can actually cause wear and tear on the teeth and also the restorative material contained in a tooth cavity, one of them is composite resin. ${ }^{1}$

A number of studies have reported that there is a relationship between tooth erosion and acidic foods and beverages such as soft drinks or packaged fruit juices, and acidic foods. ${ }^{8}$ Food and beverage ingredients contain a number of acidic materials such as citric acid, vinegar, bicarbonic acid, and others which are widely used in the field of tooth conservation as etching material in enamel or dentin teeth with a pH close to 2 to 3 . This can result in the demineralization process of enamel and hypersensitivity to dentin. ${ }^{9}$

Enamel demineralization is the destruction of dental enamel hydroxyapatite which is the main component of enamel due to chemical processes. The condition of enamel demineralization occurs when the $\mathrm{pH}$ of the solution surrounding the enamel surface is lower than 5.5 (generally the $\mathrm{pH}$ of packaged drinks ranges from 2.3 to 3.6 ) and the concentration of non-dissociating acids is higher on the surface of the enamel than in the enamel. ${ }^{10}$ The acidic atmosphere formed by drinking acidic drinks causes a decrease in salivary $\mathrm{pH}$ to a certain level, which results in saliva covering the surface of the tooth becoming unsaturated with calcium phosphate so that there is a decrease in the concentration of hydroxyapatite crystals forming ions in saliva, namely calcium and phosphate. Therefore drinks with low $\mathrm{pH}$ and contain acids are considered potentially erosive. ${ }^{11}$

The results of the study conducted showed that there was an influence of packaged strawberry juice on the surface roughness of nanofilled type composite resin. This is evident from the results 
of significant research in the treatment and control groups. The treatment group immersed in packaged strawberry juice and artificial saliva had an average surface roughness value of $0.3722 \mu \mathrm{m}$, while the control group that was only immersed in artificial saliva had an average surface roughness value of $0.2070 \mu \mathrm{m}$. The results of the study showed that nanofilled type composite resins in the treatment group experienced increased surface roughness from the control group. ${ }^{12}$

All types of drinks, such as soft drinks, fruit drinks, carbonated drinks, tea, even ordinary water can influence the properties of composite resins as well as the quality of the restoration materials of composite resin. The effects of these drinks, among other things, can change the surface roughness of the composite resin. The amount of changes in surface roughness that occurs depends on the type of drink, how long the drink is consumed, as well as the characteristics of the composite resin material used.

Many foods and drinks affect composite resin materials. Previous studies conducted show that composite resin fillers tend to be detached from resin material, and matrix components undergo decomposition when exposed to low $\mathrm{pH}$ environments. This means that drinking acidic drinks for a long time and by continuously sipping the drinks can cause erosion of enamel and also composite resin. ${ }^{13}$

All packaged fruit drinks showed a $\mathrm{pH}$ below the critical value of 5.5. PH measurement is a practical method for assessing the erosive potential of acidic drinks. Through measurements using a $\mathrm{pH}$ meter, a $\mathrm{pH}$ value of 3.07 was obtained in the packaged strawberry juice used in this study. A pH value of 3.07 indicates that packaged strawberry juice drinks include drinks that have a $\mathrm{pH}$ below the critical value. As stated in the underlying theory, an acidic atmosphere below a critical pH can cause composite resin materials to be more easily degraded, affecting surface roughness. ${ }^{14}$

The composition of packaged strawberry juice used in this study were water, strawberry fruit, sugar, fructose syrup, acidity regulator (citric acid), stabilizer, strawberry flavoring, preservative (sodium benzoate and potassium sorbate). The composition of packaged strawberry juice that can affect surface roughness of the composite directly is strawberry and acidity regulator (citric acid). Citric acid, including organic acids, are known to induce Bis-GMA to become weaker. ${ }^{15,16}$ explain that drinks containing citric acid cause more tooth erosion compared to drinks containing maleic acid at the same $\mathrm{pH}$. This is because soft drinks contain citric acid has a very low $\mathrm{pH}(\mathrm{pH} \pm 3)$ so that at the time of soft drinks containing citric acid, $\mathrm{pH}$ of the mouth reaches below a critical point that causes subsaturastion of ion $\mathrm{Ca}+2$ and $\mathrm{PO} 4-3$, thus causing the loss of ions from the teeth to the environment in the mouth.

Citric acid in strawberries is very beneficial for the human body, but its acidity is detrimental to the field of dentistry. ${ }^{17}$ citric acid erodes more quickly especially at low $\mathrm{pH}$, even at $\mathrm{pH}$ 1.5-2.5. This acid is twice as destructive to enamel as hydrochloric acid or nitric acid. Wear does not only occur in the teeth, but also in the restoration material contained in a dental cavity, one of which is composite resin. Some studies report that acidic atmosphere can degrade glass ionomer cements, polyacid modified composite resins, and composite resin restorative materials.

An in vivo study has shown that nanofilled type composite resins tend to experience greater wear than enamel. Composite resin wear is caused by several factors, including strong contact with opposing teeth, abrasion due to toothbrushes and toothpaste used, acidity due to consumption of food, fruits, drinks, or abnormalities in the stomach which can increase stomach acid which results in acidity in oral cavity, causing erosion of teeth and restorative material in the mouth.

In composite resins there is no redeposition of ions by saliva as occurs in teeth when exposed to acidic solutions. On the surface of composite resins that have been exposed to acidic drinks, the presence of saliva only serves as a rinse and neutralizing the acidic atmosphere, not helping the remineralization process so that from time to time the degradation process of the resin matrix and filler must occur and the situation cannot be reversed.

The chemical degradation process in composite resins is mainly due to the diffusion of particles into the composite resin components. Degradation is the change of chemical compounds into simpler compounds by splitting one or more atomic groups. Degradation of composite resins 
is the hydrolysis reaction of polymer ester radical because it is known that the chemical bond of the polymer is easily hydrolyzed. This degradation process can occur when the liquid diffuses. Composite resins can absorb water and other liquids in the mouth. Fluid absorption mainly occurs in the resin matrix.

The absorption of water in composite resins depends on the particle size of the filler and the quality and stability of the coupling agent. The acidic atmosphere due to low $\mathrm{pH}$ can make the coupling agent bond in the composite resin tenuous. A stable coupling agent can minimize damage of the bond between the matrix and the filling material. ${ }^{18,19}$

When the resin matrix on the surface of the composite resin absorbs the liquid, the bond between the resin matrix becomes weak, so that the filler particles can be separated from the matrix. This absorption process occurs when the positive part of a liquid molecule binds to the negative molecule of oxygen from another liquid and a hydrogen bridge is formed. This intermolecular bond causes the fluid to continue to diffuse and be absorbed by the composite resin. Very small molecules of liquid will enter between the polymer molecules of the resin matrix. The presence of an acidic atmosphere in the liquid causes the interaction of chemical separation more quickly.

Acid solutions contain high hydrogen ions $(\mathrm{H}+)$ causing the tendency of bond breaking more often. Acids are generally known as oxidizing agents and catalysts in the hydrolysis process. Damage caused by hydrolysis breaks the resin matrix bonding with the filler so that water is drawn to the surface of the filler. This results in loss of surface cohesion of the filling material so that over time the overall bonding of the resin matrix with the filling material is lost.

The breaking of the bond results in the degradation of the composite resin by the shortening of the polymer chain bond which turns into an oligomer, then returns to the monomer. The resin matrix particles and also the filler which are detached from the surface cause the surface of the composite resin to become uneven. This degradation process results in softened matrices and microscopically formed rough holes that are showed as loose fillings when the composite resin is exposed to a certain chemical or food. These large holes will cause the surface of the composite resin to become uneven thereby increasing its surface roughness.

Composite resins have been widely reported to have a tendency to cause damage due to the acidic atmosphere in the oral cavity. The rough surface of the composite resin causes many disadvantages, among which can be a place of attachment for bacteria and plaque retention so that it worsens oral hygiene, irritates gums, causes secondary caries and can develop into periodontal disease. In addition, the rough surface of the composite resin can abrasion to its antagonistic teeth when it functions. Surface roughness in composite resins can also cause discoloration to reduce the aesthetic properties of a composite resin restoration and cause discomfort to patients.

\section{CONCLUSION}

The surface roughness value of nanofilled type composite resin immersed in the packaged strawberry juice (treatment group) is 0.3722 $\mu \mathrm{m}$, while in the control group is $0.2070 \mu \mathrm{m}$ so it can be concluded that there is an influence of the packaged strawberry juice on the surface roughness of the nanofilled type composite resin.

\section{REFERENCES}

1. Ayub MJ. Ullah A. Muhammad, Zeb A. Evaluation of strawberry juice preserved with chemical preservatives at refrigeration temperature. International J Nutrition Metabolism. 2010;2(2):27-32.

2. Noort RV. Introduction to Dental Materials. London: Mosby Elsevier. 2007. 99-102 pp.

3. Roberson TM, Heymann HO, Swift JS. Sturdevant's Art and Science of Operative Dentistry. Santa Louis: Mosby Inc. 2006. 498598 pp.

4. Wattanapayungkul P, Yap AUJ. Effects of inoffice bleaching products on surface finish of tooth-colored restorations. Operative Dentistry. Singapore. 2003;28(2):15-19.

5. Badra VV, Faraoni JJ, Ramos RP, Palma DRR. Influence of different beverages on the microhardness and surface roughness of resin composites. Operative Dentistry Journal. 
2005;30(2):213-219.

6. Almeida L, Abilio GMF, Cavalcante MT, Castro RD, Cavalcanti AL. Cariogenic and erosive potential of industrialized fruit juices available in brazil. Braz J Oral Sci. 2010;9(3): 351-357.

7. Ilyas M. Perbedaan kadar kalsium dalam saliva sebelum dan sesudah mengkonsumsi minuman ringan yang mengandung asam sitrat. JITEKGI. 2006;3(1):96-99.

8. Machado CW. Lacefield, Catledge A. Human enamel nanohardness, elastic modulus and surface integrity after beverage contact. Braz Dent J. 2008;19(1):68-72.

9. Wongkhantee S, Patanapiradej V, Maneenut C, Tantbirojn. Effect of acidic food and drinks on surface hardness of enamel, dentine, and tooth coloured filling materials. Journal of Dentistry. 2006;34(8):214-220.

10. Ghazal M. Kern M. The influence of antagonistic surface roughness on the wear human enamel and nanofilled composite resin artifical teeth. The Journal of Prostethic Dentistry. 2009;101 (5):342-349.

11. Lakhdar S, Said. Research Journal Dental of Medical Science 1(2): Material wear under different $\mathrm{pH}$. University of Setif Algeria. 2007.

12. Rios D, Honorio HM, Francisconi LF, Magalhaes
AC, Machado M, Buzalaf MAR. In situ effect of an erosive challenge on different restorative materials and on enamel adjacent to these material. Journal of Dentistry. 2001;36:(9) 152-157.

13. Dorland. Kamus Kedokteran Dorland. Jakarta: EGC. 2006

14. Han LA. Okamoto M. Fukushima, Okiji T. Evaluation of flowable composite surfaces eroded by acidic and alcoholic drinks. Dental Material Journal. 2008;27(3):455-465.

15. de Almeida Pdel V1, Grégio AM, Machado MA, de Lima AA, Azevedo LR. Saliva composition and functions: a comprehensive review. J Contemp Dent Pract. 2008 Mar 1;9(3):72-80.

16. Craig RG, Powers JM. Restorative Dental Material. USA: Mosby, Inc. 2002. p. 232-244.

17. Eliades G, Eliades T, Brantley WA, Watts DC. Dental Materials In Vivo: Aging and related phenomena. Hong Kong: Quintessence Publishing Co, Inc. 2003;99-125 pp.

18. Yap AUJ, Wee KEC. Effect of cyclic temperature changes of water sorption and solubility of composite restorative. Operative Dentistry. 2002;27(1):147-153.

19. Callister, W.D. 2007. Material Science and Engineering: An Introduction. USA: John Wiley \& Sons, Inc. 155-159 pp. 